\title{
Working Beyond 60 - Introduction: Key Policy Issues and Recommendations
}

\section{Geneviève Reday-Mulvey}

The Geneva Association, 53, rte de Malagnou, Geneva 1208, Switzerland.

E-mail: genevieve_reday@genevaassociation.org

This introduction to the second part of this issue devoted to working beyond 60 provides, first, a short summary of some of the main policy issues and results of a recent book ${ }^{1}$ published by the author. It shows that demographic and pension constraints can constitute a positive challenge due to new social and employment patterns. It then analyzes how the reduction of working time and the promotion of age management can help to encourage an extension of working life. In Part 2, we provide part of chapter 9 of the book on the need for fairness, diversity, and flexibility. Part 3 summarizes key policy recommendations. The Geneva Papers (2005) 30, 604-619. doi:10.1057/palgrave.gpp.2510053

Keywords: employment; pensions; older workers; public social and employment policies; company age management

\section{Introduction}

Owing to current and future demographic changes, all EU Member States have recently adopted important pension reforms. These reforms generally include a rise in the retirement age (or an increase in the number of contribution years), greater flexibility in the age of retirement, and promotion of a lengthening of the contribution period to qualify for full benefits. Briefly put, they encourage later and more flexible retirement and the combination of pensions with income from work. Policymakers and the European Commission ${ }^{2}$ have also realized that increasing the participation rate of "older" workers is crucial to implementing these reforms and to finding real solutions to the demographic challenge. While the answer to Why work beyond 60 has now become obvious, the How and for Whom questions require more subtle responses.

In the context of its Four Pillars programme, The Geneva Association, already conscious almost 20 years ago of the need to define global policies to face the crisis of our social protection systems, proposed a flexible extension of working life (a "fourth" pillar) as one of the key solutions for the future financing of pensions. ${ }^{3}$ But extension of working life, if it is to be feasible and sufficiently widespread, has to be adapted to meet the wishes and needs of workers and companies. The Four Pillars programme

\footnotetext{
${ }^{1}$ Working beyond 60 - Key Policies and Practices in Europe, by Geneviève Reday-Mulvey, Foreword by Professor Alan Walker, Palgrave Macmillan, March 2005.

${ }^{2}$ European Commission (2003a, b).

${ }^{3}$ Delsen and Reday-Mulvey (1996).
} 
intensively worked on the idea of gradual retirement first as a bridge beween exit and pension ages and in the longer term as a "natural" way of extending work life. It pointed out that part-time and flexible work correspond to recent changes affecting labor markets, service employment, and emerging social patterns in the life cycle. It then proposed that part-time and flexible work-after- 60 policies, accompanied by other age management measures (e.g. continuing training and lifelong education), must go hand in hand with a diversity of end-of-career patterns, allowing some categories of workers to leave earlier than most other workers employed in mental abilities-based employment.

\section{Part 1. A short summary of the book Working Beyond 60}

\section{Working Beyond 60 - Why? Constraints and Opportunities}

\section{Rising retirement expectancy}

A lengthening of life was probably the most remarkable feat of the 20th century: not only has life lengthened but also the health of persons in their 60s, 70s, and 80s has improved considerably. By comparison with the situation 50 years ago, life has been extended by one or even two decades in good health. Not only does old age last longer but adult life has also gained in length, and young people now benefit from a greater number of years devoted to study. Retirement, then, commences before the onset of old age, with the result that old age itself needs to be redefined as it is no longer coterminous with retirement and even less with the age of withdrawal from active life. ${ }^{4}$ However, the main question is: how are we going to be able to finance a retirement of 20 years for men and 25 years for women (averages of retirement expectancies for the EU 15 Member States)?

Over the last 20 years, early retirement has become widespread and has progressively constituted an important social paradox and often a difficult experience for workers due to the absence of any proper transition between full employment and full retirement. The paradox of the relatively early age of exit from the labor market became increasingly evident as life and health expectancies continued to rise and as more and more 60-year olds remained active and in good health and yet almost entirely absent from the labour market. In several countries, mainly of Continental Europe (e.g. Germany, France, Italy, the Netherlands, and Austria) and in many companies (in particular large ones), it became and continues to be for many a new "social right", 5

Demographic prospects and budgetary constraints have forced OECD states to rethink thoroughly and update their social welfare systems and more particularly their pension arrangements. But the main question remains: how to work beyond 60 ? How to encourage employees and companies to find a positive approach to, respectively, continuing work and to offering employment later than they do today?

\footnotetext{
${ }^{4}$ Auer and Fortuny (2000).

${ }^{5}$ Guillemard (2003).
} 


\section{Social and employment new patterns}

The life cycle of the great majority of us has radically altered in recent years: the organization of work life into three age-based vertical periods (training, work, and retirement) is gradually giving way to a horizontal arrangement where we train, work, bring up families, spend our leisure time, and retire differently than we did in the past. Continuing training and life-long education are becoming an accepted part of life and work; part-time and flexible work have developed considerably; most people are no longer "old" at 60 or 65 (we are staying young and in good form for many more years - O. Giarini speaks of counter-ageing ${ }^{6}$ ) and many "age actively", performing voluntary and family activities that are essential for our communities. Overnight or guillotine retirement has been negative for generations of workers, and surveys show that there is a strong need for a transition from full-time work to full-time retirement. A significant cohort effect means that people retiring today (and even more so in the coming years and decades) are and will continue to be very different from current retirees who started their work life very young, often in difficult physical circumstances.

New major employment trends are favorable factors for work beyond 60 or even 65 . If we consider not only tertiary sector activities per se but also service functions in manufacturing and agriculture (such as research, planning, marketing, maintenance, storage, quality control, occupational safety and health, and distribution), well over 80 per cent of jobs in our economies are now in services, and this trend is set to continue in the years to come. Not only is part-time and flexible employment more developed in services but also most jobs in the service sector involve chiefly mental and social abilities. The latter hardly deteriorate over time and in some cases even improve with age. Not only have workforces become more feminine and older but also there exist still substantial untapped workforce reserves of women and older persons. These two categories of workers, moreover, who are frequently to be found in part-time service functions, declare themselves ready to work later than $60 / 65$ if offered flexible work opportunities. Therefore, policies which seek to help women and older workers reconcile work with family and health constraints and improve their pension rights will be making a very real contribution to meeting the challenge of "ageing". Improvements in the work environment and organization will help senior workers to stay active longer.

\section{Working Beyond 60 - How? Reduction of Working Time and Promotion of Age Management}

\section{Work-time reduction}

Work-time reduction is essential to facilitate and encourage work beyond 60 . Scientific studies have shown that workers over 60 are no less effective or productive than their younger counterparts. They often have different typical strengths and weaknesses: physical abilities decrease with age, but mental and social abilities can improve, especially if the stress level is contained. ${ }^{7}$ However, working full time after

\footnotetext{
${ }^{6}$ See, for example, The Four Pillars Newsletter, No. 27, August 2000.

${ }^{7}$ Ilmarinen (1999).
} 
60 will prove positive only for a minority of workers, the highly motivated who are often self-employed or able to work flexibly. The benefits of part-time work (and of gradual retirement) are important for employers (e.g. reduction of costs, increased productivity, lower absenteeism) as company practices show (e.g. Arcelor, Laboratoire Boiron), for employees (e.g. reduction of stress and improved health, enhanced job satisfaction, transition between full-time work and complete retirement), and even for the community (e.g. more contribution receipts, avoiding black market employment).

Part-time work can be an excellent bridge between effective exit ages (e.g. 60) and legal pension ages (e.g. 65), and is sometimes called partial early retirement. Countries such as Finland, France and Germany have had significant successful practice with similar advantages.

In the longer term, part-time work will constitute an ideal extension of work life beyond 65 for various reasons: the need to manage increasing pension ages, the need to increase the number of contribution years and improve pensions (e.g. women), the desire to remain active, useful, and integrated in one's company, and the benefits of exercising one's mental, social, and physical abilities. ${ }^{8}$

\section{Recent key public policies in EU countries}

Supra-national organizations and the social partners have had an important role in helping states to define and adopt objectives/policies to reverse early retirement trends. In particular, the European Commission has set up two main objectives for 2010: the first is a 50 per cent employment rate for 55-64 workers, the second is to increase the age at which people stop working (effective exit age) by 5 years. ${ }^{9}$

A number of EU countries have over recent years adopted a global policy or an holistic approach and can serve as an example to others: their pension reforms have been complemented by reforms of disability and unemployment systems, by employment incentives, and measures which in practice have already had positive results, such as the following.

- The exit age has increased by 2 years in Finland and the Netherlands.

- Recourse to disability has decreased in Finland, Denmark and the Netherlands.

- In all, 60 per cent of Danish firms have adopted one or several incentive-based age management measures. ${ }^{10}$

- The U.K. authorities have convinced many employers to set up flexible retirement and to adopt a code of practice, and financial incentives have helped older workers to go back to work.

- The Netherlands has encouraged atypical work, especially part time at the end of the career.

\footnotetext{
${ }^{8}$ Reday-Mulvey (2000-2005).

${ }^{9}$ European Commission (2004).

${ }^{10}$ The Geneva Association (2003).
} 
Other EU countries, most of them marked by a very early exit culture, have tried to reverse the trend and adopted specific policies with so far insufficient results:

- Germany and France have passed pension and social security reforms, for example replacing full early by partial retirement; they are now in the process of adopting fuller-scale measures.

- Italy has adopted a drastic pension reform, but has now to address the employment question.

- Switzerland is a special case of a high employment rate after 60 without official policies (except not very generous social security) and with only recently a trend towards early exit.

- Hungary has taken a drastic change of direction for pensions, but no employment results yet.

\section{Recent key age-management measures in EU companies}

Age management in enterprises ${ }^{11}$ includes: reduction of work time, gradual/flexible retirement and part-time work, career planning, continuing vocational training and life-long education, ergonomics and mobility, seniority wages, pension regulations, age diversity, anti-age discrimination, and codes of practice. For each of these measures, positive company examples are examined. Chief ones among them are as follows.

- Reduction of work time, gradual/flexible retirement, and part-time work: these measures are often relatively easy to set up, and British or other European firms have experienced benefits in retaining corporate experience and culture, improving employee satisfaction, meeting consumers' age needs, reducing absenteeism (e.g. French firms), and improving employer image.

- Career planning: Positive examples are found in German, Norwegian, and French firms (e.g. Axa France, where career planning encourages mobility of functions inside the firm).

- Continuing vocational training and life-long education, crucially important and becoming frequent in large firms in most countries, in particular in Sweden, Germany, France, the Netherlands, and the U.K.

- Ergonomics and mobility.

- Seniority wages are being modified slowly and are very important if discrimination against older workers is to be avoided.

- Pension regulations often in the past based on final salary (e.g. the Netherlands, the U.K.) are being modified and now calculated on a best 10 or 20 years basis.

- Anti-age discrimination: All EU15 member states have to pass legislation before 2006, and most have already done so, some countries having passed wider legislation (e.g. the Netherlands) than others.

- Codes of practice containing guidelines for employers and employees have been prepared by governments and adopted by companies in several countries: the U.K. Code of practice is one of the best; ${ }^{12}$ there also exists a European code of practice on age and employment.

\footnotetext{
${ }^{11}$ Walker and Wigfield (2003).

12 Taylor (2003).
} 


\section{Part 2. Who can and would wish to work beyond 60?}

\section{The need for diversity and the importance of fairness}

The need for diversity is crucially important whenever policies for extending work life are adopted and implemented by firms. This is because workers enter the labor market at different ages and in differing personal circumstances, and with a wide range of life expectancies.

\section{Extended studies and training}

Over the last two generations, a revolution has taken place in education and training in all developed countries, and overall young people now have access to much longer studies and training, and to better qualifications. They enter the world of work later than ever in the past. Although it varies from country to country, the age of entry is often at 20 years or even later. In France and Germany, for example, the average age of entering work is among the highest in the EU at, respectively, 21 and 22 years. In the U.K. it is slightly younger at around 20, and in Denmark, the lowest in the EU, it is close to 18 years. This is in stark contrast to the age at which many workers leaving their job today started work, often between the ages of 14 and 17. The age at which young people enter the labor market varies not only from one generation to the next but also within the space of a single generation, and depends mainly on the educational level of the individuals concerned. When pension systems require 40 or more contribution years, the age of entering work will of course be critical. It is precisely for this reason that many social scientists consider a single age for retirement for all a socially unfair criteria. Moreover, tasks also differ greatly from one branch and from one category of worker to the next. The building industry, for instance, is an obvious example of a branch where most workers simply cannot work for 40 years, and where diversity of end of career is absolutely essential.

Retirement age, a function of the arduousness of work?

Should therefore the age of retirement be a function of the arduousness or of the inherent stress of a job? Yes, in principle, and it is precisely for this reason that different ages for retirement have already been put in place, for people, among numerous others, like firemen, military personnel, and airplane pilots. Nowadays all countries have a number of specific retirement conditions for specific categories of worker.

In Switzerland, the retirement age for women is currently increasing and, following advice by the OECD, an increase to 67 years for all workers is now contemplated. Yet, a few years ago, the retirement age for builders was reduced from 65 to 60 years in recognition of the difficult conditions builders have to face, but also in order to bring down the high disability rate among workers in that sector.

If the factor just described accounted for retirement at an early age in some branches in the past and to some extent still today, in many occupations things have improved. Coal miners who in times past performed extremely hard jobs are, in most, if not all, of our European states pretty well extinct and driving a TGV, and though in many respects this job involves greater responsibility it is not as physically arduous as driving a steam locomotive 50 or 60 years ago. Must the privileges and special 
concessions of the past be maintained when conditions have changed? Almost certainly not. And yet, the second halves of many careers need reassessment and extensive redesign to include functions which are less active and more sedentary in nature. Alternatively, for example, firemen or nurses who need to retire before their peers, could find other part-time tasks in other fields. Education, cultural pursuits, and training, for instance, offer numerous opportunities for second "careers".

Examples are common. A few are given as illustrations of our purpose, and the reader will have additional examples in mind. Hospital nurses from the age of 55 often find it difficult to continue working full time. However, they possess experience, knowledge, and often empathy. They can be assigned to other tasks, for example to call centres in hospitals (e.g. for emergencies), work in schools, to organization of long-term care services for elderly people in urban areas, visits to sick elderly persons who need a quality of contact, and moral comfort or mobile blood transfusion units. Teachers also find it difficult to teach after the age of 55 or 30 years of teaching. They often could reduce their working time and be employed at other paid tasks (libraries, bookshops, private tuition, work in non-governmental agencies, etc.). Civic jobs in town halls and municipal councils are well performed by experienced persons from various backgrounds and would therefore constitute valuable second careers.

\section{Different life expectancies}

But can the arduousness of a job or function actually be measured? Measurement is certainly difficult to do especially when working conditions are changing constantly. One more obvious approach to the problem is to examine life and health expectancies where data for the latter exist. In France, on average, at 35 years the life expectancy of a domestic employee is 36.5 years and that of a qualified blue-collar worker is 37 years. On the other hand, civil servants, artists, and intellectual workers all have a life expectancy of around 46 years. These significant differences in life expectancy from one category of worker to the next are twice as great for men as for women. ${ }^{13}$

For these reasons, the notion of retirement age should be gradually replaced by that of the number of contribution years to pension systems. It is essential that in future pension schemes be based on more objective and fairer criteria than hitherto. Reforms like those adopted in Sweden ${ }^{14}$ have been very much on these lines. It has been suggested, incidentally, that, save for special cases where early exit is a compensation for certain recognized disadvantages, the situation of public sector workers should now be brought into line with those in the private sector. Most countries, and Italy is one example, have already been able to meet these criteria. Others like France still suffer from wide disparities in the age and conditions of pensions.

If then, for sound economic and financial reasons, society expects workers to remain longer in the labor market, the need for a diversity of ends of career must equally be accepted. The public debate on this issue and the policies to which it gives rise must therefore accommodate a limited number of exceptions to a later exit age, which will help to confirm the new rules and consolidate future practice. In other words, if major

\footnotetext{
${ }^{13}$ Conseil Economique et Social (2001).

${ }^{14}$ Reday-Mulvey (1999, pp. 461-472).
} 
resistance to the new measures is to be avoided, employers and the public authorities must ensure that the new policies pave the way for a wide range of end-of-career options and modes of transition into retirement. ${ }^{15}$ Such diversity would no more than reflect the characteristics of the sectors, professional branches, categories of workers and individuals, and cultural preferences involved.

\section{The need for flexibility and the importance of informed choice}

In most European countries, labor-market flexibility has increased considerably over the last quarter century. The new functions of our service economies have greatly contributed to promoting and broadening this trend and atypical work has now gained enormous ground. Flexible work time is crucial not only for young parents who need to combine work and family responsibilities but also for end-of-career employment: it makes the extension of work both possible and necessary. However, extension of work life full-time is likely to be possible only for a few categories of worker, for example the self-employed whose work patterns are in any case inherently more flexible, and workers who are in very good health and personally committed to what they do. Meanwhile, the average employee will in all probability be more ready to work later if he or she can work part-time and thus enjoy the benefits of more leisure and more time for activities outside the work place. Employers also stand to gain since it is now established that part-time work reduces absenteeism and the cost of the senior worker. In short, such an arrangement, for both the employee and for the company concerned, will make for a smoother transition between work life and full retirement. Firms all over Europe that have in this way developed an extension of work life part-time have been found to be highly satisfied with the results.

\section{Working longer - an unavoidable obligation}

A high proportion of workers of the baby-boom generation will need to work later because of pension reforms. Moreover, a fair proportion of those working part-time for a good part of their career - this mainly concerns women, but increasingly men as well - will need to work longer to improve their second pillar pension.

But, for the time being, not only are women more accustomed to part-time, and flexible and temporary work patterns, but also, because of their smaller contribution and careers that are often interrupted for family or care reasons, their pension rights are frequently poor when compared to those of men with the same level of qualification. In spite of the gradual convergence of national pension systems across the EU, the European Commission acknowledges that "significant coverage discrepancy in pension entitlements, particularly under second pillar schemes, of women atypical workers will persist for a long time to come". As a consequence, in the U.K., for example, a recent publication ${ }^{16}$ shows that one in four single women pensioners lives in poverty, and twice as many women as men rely on means-tested benefits in retirement. Fortunately, the rates in most other EU 15 Member States are

\footnotetext{
${ }^{15}$ Conseil d'Analyse Economique (2000).

${ }^{16}$ Age Concern England (2003).
} 
not as alarming. However, the majority of women, in particular those ageing alone (whether divorced, widows or single), will need to work beyond the pension age in order to bring their income and pension benefits up to acceptable standards.

Given that women's life expectancy is definitely longer than men's in most countries, is it fair that women should work longer than men? Whatever answer we give to that question, it is our belief that both women and men should be encouraged to work later (and to continue to train until the end of their active life), in particular on a part-time basis, so as to continue to contribute to economic life and to optimize their pension benefits. It is, however, also a fact that women, as a general rule, bear a greater load than men in terms of being primarily responsible for the care of children, and of the elderly and sick persons within the family and community. It is not rare, for example, for women around 60 to be still responsible for ageing parents or in-laws, and it is they who in practice perform most of the caring. As grandmothers, they also play a key role in assisting with the bringing up and education of young children, and are often the only way their daughters and daughters-in-law can combine a family with work. It is also recognized that women often make up the majority of workers in voluntary organizations. Indeed, worldwide, it is women who still perform by far the main bulk of unpaid (i.e. non-monetarized, however essential to the community) work, while men do most of the paid work. In spite of encouraging convergence with work cycles, the roles of men and women remain essentially complementary. And for these reasons, if for no others, the European Commission is promoting gender-neutral pension systems and schemes.

\section{Importance of informed choice}

Flexibility is also crucially important at the end of the career because, if workers are to remain later on the labor market, they must be motivated and productive, and they will be neither of these things unless they have freedom of choice - an all-important modern value - in the matter. They must be made perfectly aware of the alternatives on offer: basically, leaving earlier on a reduced pension or staying on so as to benefit later from a more generous one, hence the need for workers to receive regular statements of their pension benefits as a function of the number of years worked (e.g. the "orange" annual Swedish pension bulletin).

But the realities of an individual's everyday life cannot and should not change from one day to the next. It is important therefore that they extend work life for a few more years than they do today to optimize pension benefits and to provide for a smooth transition from full-time work to full retirement. But, in turn, it is important also that this extension be flexible and, for the most part, part-time, and that its terms and conditions be freely consented to and fully desired by the individual concerned. In short and in other words, retirement should become a process rather than the event it still is most of the time.

\section{Part 3. Key policy recommendations}

Successful extension of occupational life requires that certain pre-conditions be met. All new policies, any measures taken by the authorities, any significant 
change in enterprise culture, will need to be preceded by a coherent, thoroughly democratic, broad-based, and informed debate of the issues involved. In this regard, there are lessons to be learned from the example of the Nordic countries. It is also essential that all regulations governing pensions, social insurance, and tax arrangements be made to serve the same end: that of extending occupational life. Within the enterprise, such extension must be accompanied by an adjustment of work schedules, and countries with high rates of qualified part-time workers will find the going a lot easier. Similarly, continuing training until the end of the career will be crucial in keeping productivity and motivation at optimum levels. And lastly, part-time work will exercise downward pressure on the cost of senior employees. We shall briefly examine four main recommendations regarding the need (1) for an holistic approach, (2) for coordinated social and economic policies, (3) for a lively and well-informed debate, and (4) for an effective and rapid plan of action.

\section{The need for an holistic approach}

Countries such as Finland, Denmark, and the U.K., which have been so far successful in flexibly extending work life, are all countries that have adopted a global approach to healthy and active ageing and end-of-career management. Most actors today, at almost all levels - the European institutions, national governments, companies, and the trade unions - are convinced of the wisdom of this approach. And this is now seen to be especially true of countries like Germany, France, Italy, Austria, and the Netherlands, where the early retirement culture has been particularly pronounced. It is only when all variables - pension reforms, social welfare regulations, employment, and company policies - start to change that attitudes, norms, and behavior will progressively alter with all actors of economic and social life. And let us remember that long-term issues need global policies sustained over time to be successful. The following graph shows not only that social and economic policies need to be properly coordinated but that they need to take into account company age management and new life-cycle patterns. It now becomes clear that, if we need pension reforms, we need to accompany them by a root and branch reassessment of the overall end-of-career and retirement contexts within which they will need to operate (Figure 1).

\section{The need for coordinated social and economic policies}

As early as 1996, a Japanese expert, I. Shimowada, concluded "One can hardly overstress the importance of properly integrated public and company policies for promoting the employment of older people". ${ }^{17}$ Indeed, in the 90 s, most western countries adopted pension reforms, but it is only more recently that governments realized that, to encourage longer working lives, social reforms had to be accompanied by employment measures at the state and company levels.

\footnotetext{
${ }^{17}$ Delsen and Reday-Mulvey (1996, p. 162).
} 


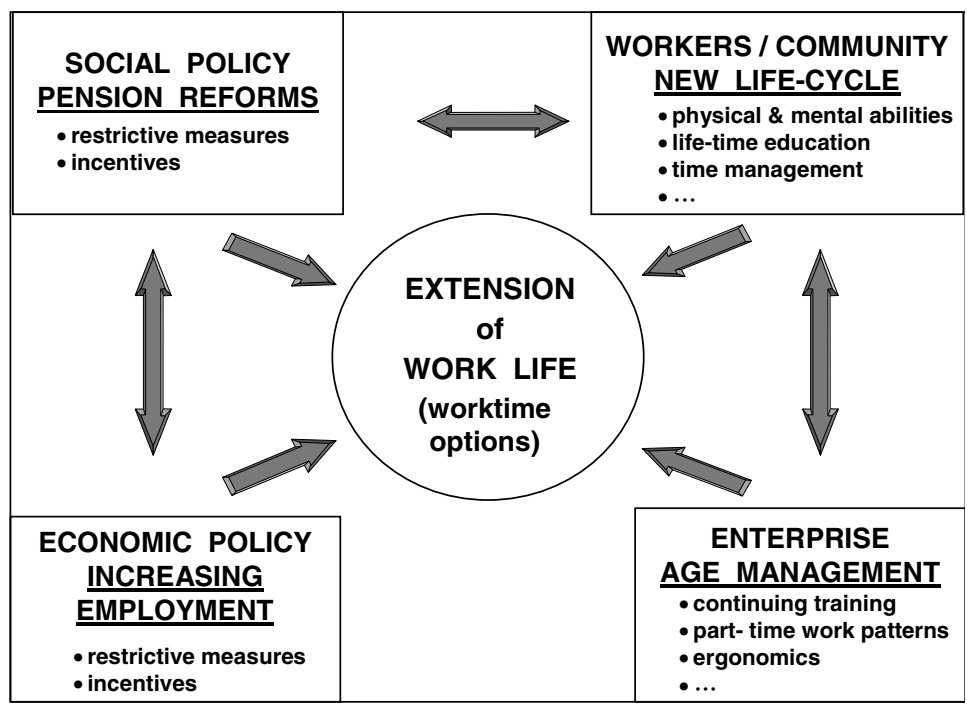

Figure 1. The model of working beyond 60. Source: G. Reday-Mulvey, in Report Avenir Suisse, 2002.

Public policies: the need for restrictive measures and incentives

What stands out as essential is that public policies need to be sufficiently comprehensive and accompanied by incentives at various levels. In order to reduce exit roads from work at an early stage, it is essential to accompany pension reforms by other welfare changes, in particular to make early retirement options as well as disability and unemployment routes more difficult, more costly, and their terms more stringent. But, restrictive changes of this kind clearly need to be accompanied by government-funded financial incentives. Both carrot and stick are needed in order to stimulate new attitudes and behaviors. Changing the deeply rooted mindsets of the early retirement culture requires drastic redesign, a good partnership between government and enterprise in the gradual implementation of new age management policies.

\section{Company policies: the need for comprehensive working life measures}

Four areas at least, among the many that require attention, should be a particular focus for this integrated policy approach. First, training. In order for older workers to remain competitive, continuing training should not terminate at 45 or 50 years but should persist until the end of the career and be better adapted to experienced workers (Figure 2). Countries where such company policies already exist are in a much stronger position. In Sweden ${ }^{18}$ and Switzerland, the extent of training is impressive throughout work life and there seems to be little discrimination towards older workers. In France and Germany, especially in bigger companies, a similar policy approach is now gaining ground. What is required is an extensive redesigning of the second part of the career in order to give new shape and identity to work life between 45 and 65 .

18 The Geneva Association (2004). 


\begin{tabular}{|c|c|}
\hline \multicolumn{2}{|c|}{$\begin{array}{c}\text { SOCIAL POLICY } \\
\text { Pension Reforms }\end{array}$} \\
\hline \multirow[t]{2}{*}{$\begin{array}{l}\text { Restrictive Measures } \\
\text { - raising the labour-exit age } \\
\text { - increasing the number of contribution years } \\
\text { - reducing benefits slightly } \\
\text { - devising new modes of financing } \\
\text {-... }\end{array}$} & $\begin{array}{l}\text { Incentives } \\
\text { - developing } 2 \text { nd pillar pensions } \\
\text { - encouraging personal pensions (3rd pillar) } \\
\text { - strenghening the link between pensions and contribution years } \\
\text { - fostering flexible, à la carte retirement } \\
\text { - allowing a cumulation of the pension with earnings from work } \\
\text {-... }\end{array}$ \\
\hline & OF WORK LIFE \\
\hline $\begin{array}{l}\text { Restrictive Measures } \\
\text { - reducing early retirement access } \\
\text { - reducing disability benefit access } \\
\text { - reducing unemployment benefit access } \\
\text {-... }\end{array}$ & $\begin{array}{l}\text { Incentives } \\
\text { - reintegrate workers aged } 55 \text { years and more } \\
\text { - increasing the participation of women } \\
\text { - adjusting work conditions at the end of career : } \\
\text { continuing training, part-time work, ... } \\
\text { - making labour exit more flexible } \\
\text { - providing incentives in the form of subsidies } \\
\text { - enacting anti-discrimination laws } \\
\text { - fostering good practice (codes etc.) } \\
\text {-... }\end{array}$ \\
\hline \multicolumn{2}{|c|}{ ECONOMIC POLICY } \\
\hline \multicolumn{2}{|c|}{ Employment : increasing the participation of +55 year olds } \\
\hline
\end{tabular}

Figure 2. Coordinating social and economic policies. Source: G. Reday-Mulvey, The Geneva Association, 2003 .

Second, a key variable is pay policy. It is clear that seniority-based pay policy, by raising the wage costs of workers at end of career, has constituted a real obstacle to all forms of extension of work life. The growing trend in wage calculation today towards reducing the weight of the seniority factor and increasing that of performance must be encouraged. The financial needs of senior workers are usually lower than those of workers in their 40s. Moreover, changes in pension calculation mean that wages at the end of the career no longer need to be the highest. This will enable companies to link pay to performance and not exclusively to age.

Third, part-time pay is obviously an important variable in helping to reduce the cost of the senior worker. Part-time work must be accompanied by better social protection and in-house promotion. Most companies have improved conditions of part-timers, and some countries - France and the Netherlands are examples - have modified legislation to this end.

Fourth, and finally, occupational pensions have to be adapted to longer and more flexible life cycles. Although there has been progress, particularly in England and the Netherlands, in modifying them to make them average-salary based, pension funds in many other countries are still final-salary based.

\section{The need for a lively and well-informed debate}

Another factor crucial to the effectiveness of policies promoting a longer work life is the extent to which their purpose has been communicated to, and accepted by, the public through a well-informed, broad-based debate of the issues. The experience of 
countries so far that have successfully implemented policies and measures in this area shows that the issues must be properly communicated to, and thoroughly debated by, all parties concerned - employers, employees, and trade-unions - in intelligible terms. Moreover, enterprises need a long-term approach to investment and to changing mindsets and attitudes. Hence, the importance of targeted information campaigns, of raising public awareness, and of organizing an open debate within firms, trade unions, and the general public. Also, the media have of course an essential part to play in conveying a new message: that today the onset of old age is occurring later and that the way we manage our lives between the ages of 50/55 and 70 needs serious reappraisal. Firms must now initiate a democratic debate of these issues and encourage wider discussion with decision-making bodies and the press. The ideas that underpin the new thinking on ageing must be couched in new language which is both intelligible and innovative. Experience - A National Treasure (Finland), Active Ageing (worldwide) or Age Positive (U.K.) are all examples of this and important first steps in changing people's prejudices and attitudes.

\section{The need for an effective and rapid plan of action}

Some experts believe that it is only when the labor market has experienced acute manpower shortages - depending upon the country, this will occur in from 4 to 10 years - that the majority of enterprises will move their policies towards retaining workers later than they do today and adapting work conditions accordingly. In many of the Danish and English companies that are models precisely in this area - having adopted a new approach - the change was triggered by experience of manpower shortage. It is our contention, however, that it is now time that governments plan for and anticipate this kind of contingency as part of a global strategy on ageing and work rather than wait for shortages to occur before taking action. Dramatic changes in the dependency ratios mean that in most countries the well-being of the population overall will soon depend on fewer workers. By 2010 workers over 45 will account for 40 per cent of available manpower in the EU. Workers in general - not just young workers will be in short supply and in some places already are. All ages will need to lend a hand and ageing workers will therefore hold a key position, because of their number, quality, and experience. Moreover, public and company policies need to be implemented on a certain scale and over time before change can come about.

\section{Additional policies}

We shall be looking at some additional policies we feel to be desirable. These latter fall into three distinct categories.

\section{The need for increasing employment participation overall and for controlled immigration}

The first measure concerns an increase in employment overall, but on this occasion by raising the participation rates of three specific categories of potential workers: women, the unemployed, and the disabled. As we have seen, there are important differences in the labor-market participation rates for these three categories in the EU Member 
States. The Nordic countries, for example, are doing better than the EU Southern States, but in the long term the convergence principle should help to improve these rates almost everywhere. Part-time work is here also a key factor in particular for women and disabled persons. Not only is part-time work an excellent transition between non-activity and activity but also it allows a better combination of work with family responsibilities, and so may contribute to a higher fertility rate for women.

This change calls for more active employment measures and less passive social protection. Countries such as the Netherlands, Finland, Denmark, Sweden, and others have set up excellent special measures to help disabled persons to enter the market, which include "soft" jobs, frequently on a part-time basis. Other Member States (Austria, France, Germany, Ireland, and the U.K.) have set national targets for employment of the disabled.

Another solution, much debated in recent years, is to increase, where realistic, immigration into EU Member States. The $\mathrm{UN}^{19}$ and the OECD have both estimated the number of new migrant workers required to compensate for demographic change and for a future shrinking of the labor force. According to a UN estimate in 2000, for example, the number of migrants needed to keep constant the size of the population in labor force age in France and the U.K. is about double the level recorded for the early 1990s. For the same purpose, Germany's requirement would be about 3.4 million migrants per year, that is, more than 10 times the annual number of migrants entering Germany between 1993 and 1998. In the case of Germany, for example, the sheer number involved would cause severe social and political problems. This is why in Germany and in many other cases, we would advocate as a complementary solution some form of controlled immigration.

\section{The need to reinforce family policies}

The second kind of measure or solution, in our view more important than immigration, is family policy designed to promote a stable increase in fertility rates over the long term in Europe. Various surveys have shown that women do not have the number of children they would like to have. We believe that there is a correlation, both direct and indirect, between appropriate family policies and the fertility rate.

Appropriate family policy must include, among many other things, generous family allowances, a tax system that encourages large families, the availability of adequate care provision for children and other dependants, and a better work-life balance. The differences in women's employment rates with and without children are particularly pronounced in Ireland (16.3 per cent), in Germany (21.4 per cent), and in the U.K. (22.8 per cent). In these countries, as well as in others like Spain or Greece where the differences are by comparison more modest, the care services available are woefully incapable of meeting demand. In countries with better care facilities such as Sweden (1.7 in 2002) or France (1.9), fertility rates are higher than in the EU Southern States. ${ }^{20}$

The example of Norway is in this connection rather interesting. It is one of the countries with the best fertility rates in Europe (1.8), but also with one of the best rates

\footnotetext{
${ }^{19}$ United Nations (2000).

${ }^{20}$ Godet (2003).
} 
for female employment. All very intriguing until we learn that, in Norway, companies attract women workers by offering them excellent child-care facilities.

In short, family policy will be crucially important if Europe is to secure higher fertility rates over the long term and so avoid the pitfalls of an "old" society with a diminishing population and workforce.

\section{The need for improving the quality of work}

The three glorious post-war decades were followed by a 20 -year period during which leisure pursuits, the family, and free time acquired increasing significance while work values tended to decline. European countries have reduced work time, work conditions have been personalized and made more flexible, holidays are longer than they were, and travel and leisure time are now standard for the vast majority of the population.

If active ageing is to become a widespread phenomenon, then work and its place in our lives need to be reconsidered. We need at all costs to improve the quality of work if we want more people in their $50 \mathrm{~s}$ and $60 \mathrm{~s}$, and perhaps even $70 \mathrm{~s}$, to modify their work/ leisure balance in favor of more work. As mentioned earlier, workers in low-quality jobs withdraw from the labor market 2-4 years before workers in good-quality employment. The cohort effect - with more and more workers being better qualified, working flexibly in service activities, and benefiting from continuing training and life-long education will allow more easily than in the past later exit patterns and more flexibility.

Perhaps one of the greatest challenges facing us today is that of better organizing our service society where the demand for so many of the "traditional" services remains unmet. We need to be rethinking work and retirement as parts of an integrated continuum where reform of one calls for transformation of the other. Raising the number of contribution years to our pension schemes is simply inconceivable without a thorough reappraisal of work and employment. Requiring that companies provide an employee with sufficient work until 65 or later is simply not enough. The activities and functions provided, whether paid or unpaid, must involve work that is satisfying and fulfilling, and this throughout the occupational span from entry into the labor market until exit. ${ }^{21}$

Our societies should not have to choose between leisure and work but be able to opt for a satisfactory balance between the two. What is true at the individual level is also true at the society level between welfare and workfare. This new reassessment is urgent so that, in a few years or decades, work will almost naturally last a few more years.

Today, facing both the demographic challenge and the anticipated shrinking of the work force, we need to rediscover the value and the taste of working. Of course this means rethinking and improving working conditions. More and more firms will soon offer better conditions to maintain older workers later than today. But conditions need to be humanized for all by encouraging more flexible rhythms, adequate education, ergonomics and health at work, and making working life more compatible with care activities and voluntary commitments important for the community, in particular an older one. Our societies have evolved from manufacturers of industrial produce to communities where the service-information economy predominates and where, as a

\footnotetext{
${ }^{21}$ Buck and Dworschak (2003).
} 
consequence, the organization of work is changing radically. Progressively, and increasingly in future, our societies will be marked by an older population whose maturity will gradually replace today's cult of youth to give the values of solidarity and social utility the place they deserve.

\section{References}

Age Concern England (2003) One in Four - A Quarter of Single Women Pensioners Live in Poverty: This Scandal Must End, from http://www.ageconcern.org.uk.

Auer, P. and Fortuny, M. (2000) Ageing of the Labour Force in OECD Countries: Economic and Social Consequences, Employment paper 2000/2, Employment Sector, International Labour Office, Geneva.

Buck, H. and Dworschak, B. (2003) Ageing and Work in Europe: Strategies at Company Level and Public Policies in Selected European Countries, in the series: Demography and Employment, Stuttgart.

Conseil d'Analyse Economique (2000) in R.D. Taddei (ed.), Retraites Choisies et Progressives, Paris: La Documentation Française.

Conseil Economique et Social (2001) Les personnes âgées en France, Paris: Conseil Economique et Social.

Delsen, L. and Reday-Mulvey, G. (1996) Gradual Retirement in the OECD Countries, Aldershot, U.K.: Ashgate.

European Commission (2003a) 'Adequate and sustainable pensions', Joint Report by the Commission and the Council, Directorate-General for Employment and Social Affairs, Unit E.2, Brussels.

European Commission (2003b) Recent Reforms of Pension Systems: An Assessment Framework, ECFIN/440/ 03-EN, Brussels.

European Commission (2004) Increasing the Employment of Older Workers and Delaying the Exit from the Labour Market, Communication from the Commission to the Council, the European Parliament, the European Economic and Social Committee and the Committee of the Regions, COM 2004, 146 Final, Brussels.

Godet, M. (2003) Le Choc de 2006: Pour une société de projets, Paris: Odile Jacob.

Guillemard, A.M. (2003) L'âge de l'emploi: Les Sociétés à l'épreuve du vieillissement, Paris: Armand Colin.

Ilmarinen, J. (1999) Ageing Workers in the European Union: Status and Promotion of Work Ability, Helsinki: Employability and Employment.

Reday-Mulvey, G. (ed.) (1999) 'Studies on the Four Pillars', The Geneva Papers on Risk and Insurance Issues and Practice 24(4): 461-472.

Reday-Mulvey, G. (ed.) (2000-2005) The Four Pillars Newsetters 26-36, Geneva: International Association for the Study of Insurance Economics.

Taylor, P. (2003) 'New policies for older workers, in Transitions after 50 Series, Joseph Rowntree Foundation, Bristol: The Policy Press, URL: http://www.jrf.org.uk/bookshop.

The Geneva Association (2003) 'Contributions given at the "Work Beyond 60 conference", , Vienna, March 2003, Etudes \& Dossiers No. 271, International Association for the Study of Insurance Economics, Geneva.

The Geneva Association (2004) 'Contributions given at the "Health, Work and Ageing Conference", Trieste, October 2004, Etudes \& Dossiers, No. 287, International Association for the Study of Insurance Economics, Geneva.

United Nations Population Division (2000) Replacement Migration: Is it a Solution to Declining and Ageing Populations?, New York.

Walker, A. and Wigfield, A. (2003) Older workers skills and employability: A guide to good practice in age management, working paper, University of Sheffield.

\section{About the Author}

Geneviève Reday-Mulvey is Head of the Four Pillars Research Programme at The Geneva Association and author of the newly released book Working Beyond 60: Key Policies and Practices in Europe. 